\title{
BMJ Open Cohort profile: workers' compensation in a changing Australian labour market: the return to work (RTW) study
}

\author{
Christina Dimitriadis, ${ }^{1}$ Anthony D LaMontagne, ${ }^{2}$ Rebbecca Lilley, ${ }^{3}$ \\ Sheilah Hogg-Johnson, ${ }^{4}$ Malcolm Sim, ${ }^{1}$ Peter Smith ${ }^{1,4,5}$
}

To cite: Dimitriadis $C$, LaMontagne AD, Lilley R, et al. Cohort profile: workers' compensation in a changing Australian labour market: the return to work (RTW) study. BMJ Open 2017;7:e016366. doi:10.1136/ bmjopen-2017-016366

- Prepublication history for this paper is available online. To view these files please visit the journal online (http://dx.doi. org/10.1136/bmjopen-2017016366).

Received 9 February 2017 Revised 17 July 2017

Accepted 14 August 2017

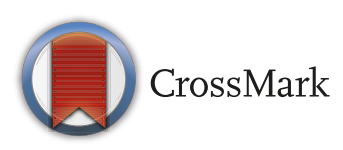

${ }^{1}$ Department of Epidemiology and Preventive Medicine, School of Public Health and Preventive Medicine, Monash University, Melbourne, Victoria, Australia ${ }^{2}$ Centre for Population Health Research, School of Health and Social Development, Deakin University, Burwood, Victoria, Australia

${ }^{3}$ Department of Preventive and Social Medicine, University of Otago, Dunedin, Victoria, New Zealand

${ }^{4}$ Institute for Work and Health, Toronto, Ontario, Canada

${ }^{5}$ Dalla Lana School of Public Health, University of Toronto, Toronto, Ontario, Canada

Correspondence to Christina Dimitriadis; christina.dimitriadis@monash. edu

\section{ABSTRACT}

Purpose Workers' compensation claims for older workers and workers who have suffered psychological injury are increasing as a proportion of total claims in many jurisdictions. In the Australian state of Victoria, claims from both these groups are associated with higher than average wage replacement and healthcare expenditures. This cohort profile describes a longitudinal study which aims to investigate differences in the return to work (RTW) process for older workers compared with younger workers and claimants with musculoskeletal injuries compared with those with psychological injuries.

Participants This prospective cohort study involved interviewing workers' compensation claimants at three time points. The cohort was restricted to psychological and musculoskeletal claims. Only claimants aged 18 and over were recruited, with no upper age limit. A total of 869 claimants completed the baseline interview, representing $36 \%$ of the eligible claimant population. Ninety-one per cent of participants agreed at baseline to have their survey responses linked to administrative workers' compensation data. Of the 869 claimants who participated at baseline, $632(73 \%)$ took part in the 6-month follow-up interview, and 572 (66\%) participated in the 12-month follow-up interview. Findings to date Information on different aspects of the RTW process and important factors that may impact the RTW process was collected at the three survey periods. At baseline, participants and non-participants did not differ by injury type or age group, but were more likely to be female and from the healthcare and social assistance industry. The probability of non-participation at follow-up interviews showed younger age was a statistically significant predictor of non-participation. Future plans Analysis of the longitudinal cohort will identify important factors in the RTW process and explore differences across age and injury type groups. Ongoing linkage to administrative workers' compensation data will provide information on wage replacement and healthcare service use into the future.

\section{INTRODUCTION}

Workers' compensation refers to a system with a central mandate of compensating workers who have sustained a work-related

\section{Strengths and limitations of this study}

This longitudinal cohort is one of the first designed to compare the return to work process of claimants with work-related musculoskeletal injuries and psychological injuries.

- The survey content included questions regarding the different aspects of the return to work process (eg, interactions with supervisors and claims agents) and any important factors that may impact the return to work process (eg, work characteristics, selfefficacy).

- Linkage to administrative workers' compensation data will allow examination of wage replacement and healthcare service use prior to, and in between interviews, as well as longer term administrative follow-up of participants.

- As claimants were interviewed on average 3-4 months after their claim was accepted, recall of certain details such as preinjury work environment may be challenging.

- The overall baseline recruitment rate of $36 \%$ is also a potential limitation; however, a high retention rate was achieved at follow-up, with response rates of $73 \%$ at first follow-up and $66 \%$ at second follow-up.

injury or illness ${ }^{\mathrm{i}}$ for both loss of employment income (wage replacement) and the cost of healthcare and associated services related to the injury. Workers' compensation systems are the primary system involved in the management of work-related injuries and illnesses in many jurisdictions, in countries such as Australia, New Zealand, Canada, Germany and the USA. In Australia, various state, territory and commonwealth workers' compensation systems cover approximately $86 \%$ of the workforce, equating to approximately

'The term 'injury' and 'injuries' will be used to refer to both injury/injuries and illness/illnesses for the remainder of the paper. 
10.5 million workers. ${ }^{1}$ In the 2011-2012 financial year, there were just over 128000 workers' compensation claims accepted that involved a week or more of incapacity from work, with the total expenditures of workers' compensation agencies in Australia being $\$ 7.8$ billion (AUD). ${ }^{1}$

A system of compulsory insurance was first introduced in New South Wales in 1926 and formed the model for most workers' compensation systems in Australia. ${ }^{2}$ These systems were originally designed in a labour market where workplace hazards were easily identifiable, and the resulting workplace injuries were easily diagnosed, with relatively clear treatment guidelines in place. ${ }^{3}$ Since the development of workers' compensation systems, there have been important changes in the composition of the Australian labour market, the types of injuries sustained and the demographic profile of injured workers and workers' compensation claimants. In particular, compensation claims from older workers and workers who have suffered psychological injury are increasing in many Australian jurisdictions. ${ }^{4-6}$ Claims for psychological injury and claims from older workers are associated with above average wage replacement and healthcare expenditures. ${ }^{4-8}$ These changes are not limited to the Australian labour market, with an ageing workforce also observed in various European countries, ${ }^{9} \mathrm{Canada}^{10}$ and the USA. ${ }^{11}$ In addition, concern regarding the rise of mental health problems and the associated impact on workers' compensation claims is highlighted in numerous international studies. ${ }^{12-14}$ These changes have important consequences for the effectiveness of policies and programmes designed to prevent workplace injury and facilitate recovery and return to work (RTW).

Various studies show that RTW is influenced by factors at the system, workplace and healthcare provider levels ${ }^{15-17}$; however, much of this research has been generated from studies on work-related back and upper extremity musculoskeletal (MSK) conditions. ${ }^{18-23}$ The extent to which these findings are directly transferrable to other types of injuries is not known. ${ }^{24}{ }^{25}$ Further, while age is often included as a covariate in research studies, few studies have specifically examined factors associated with age differences in the RTW process. As a result, it is not currently well understood whether factors that are important for RTW for people with MSK conditions are the same as those for workers with psychological conditions, and what differences exist in the RTW process between younger and older claimants.

The RTW study was established to identify factors that influence the RTW process at the individual, workplace and system levels, and how these factors impact disability, recovery expectations, self-efficacy to RTW and actual RTW and work productivity. Disability, recovery expectations, self-efficacy to RTW and actual RTW were each measured with a dedicated section in the questionnaire (named accordingly), and work productivity was measured using questions from the Work Limitations
Questionnaire with some modifications to address specific aspects of psychological conditions. ${ }^{26}$ In particular, the study aims to investigate differences in the RTW process for older versus younger workers and for claimants with psychological versus MSK injuries. Important knowledge gaps will be addressed regarding the RTW process and whether specific strategies are required for older claimants or workers with psychological injury.

\section{COHORT DESCRIPTION \\ Context}

In Victoria, approximately $85 \%$ of the labour market has workers' compensation coverage through WorkSafe Victoria (WSV). ${ }^{1227}$ In addition to wage replacement and healthcare expenditure, WSV provides insurance for lump sum compensation payments where there is a significant permanent loss of income due to serious injury. ${ }^{2}$ Although compulsory insurance through WSV covers the majority of the labour market, workers who are self-employed, sole traders or independent contractors are exempt. ${ }^{1}$ In general, standard workers' compensation claims in Victoria are those that have resulted in an absence from work for 10 or more days due to a workplace injury, with the first 10 days of absence being paid for by the employer. Injuries covered by workers' compensation are not limited to physical injuries and include psychological (mental) injuries which are caused through the course of the worker's employment or situations where a pre-existing mental condition reoccurs or is aggravated or accelerated due to work. ${ }^{28}$ It is important to note that mental conditions that result from reasonable grounds, such as appraisal of the worker's performance, disciplinary action including dismissal, are excluded from coverage by workers' compensation. ${ }^{29}$

\section{Sample size considerations}

A preliminary analysis of WSV administrative data indicated that $80 \%$ of claimants are no longer receiving wage replacement at 6 months and $90 \%$ of claimants are no longer receiving wage replacement at 12 months. Absolute differences across age groups in the proportion of claimants who are receiving wage replacement are approximately $15 \%$ at 6 months and $10 \%$ at 12 months between younger workers (less than 30 years) and older workers (55+ years), with similar differences also observed between physical and psychological injury claims. To ensure adequate statistical power to detect similar differences in RTW outcomes in our sample, 576 respondents were required to complete the 12-month interview, where $20 \%$ of the sample were older workers and $20 \%$ were workers with a psychological injury. This sample size would also allow detection of relative risk estimates of 1.7 and higher for outcomes with a $20 \%$ prevalence, and risk estimates of 1.9 and higher for outcomes with a $10 \%$ prevalence. Assuming 40\% attrition over a 12-month period, a target sample of 960 respondents was required at baseline, with $192(20 \%)$ psychological injury claimants and 


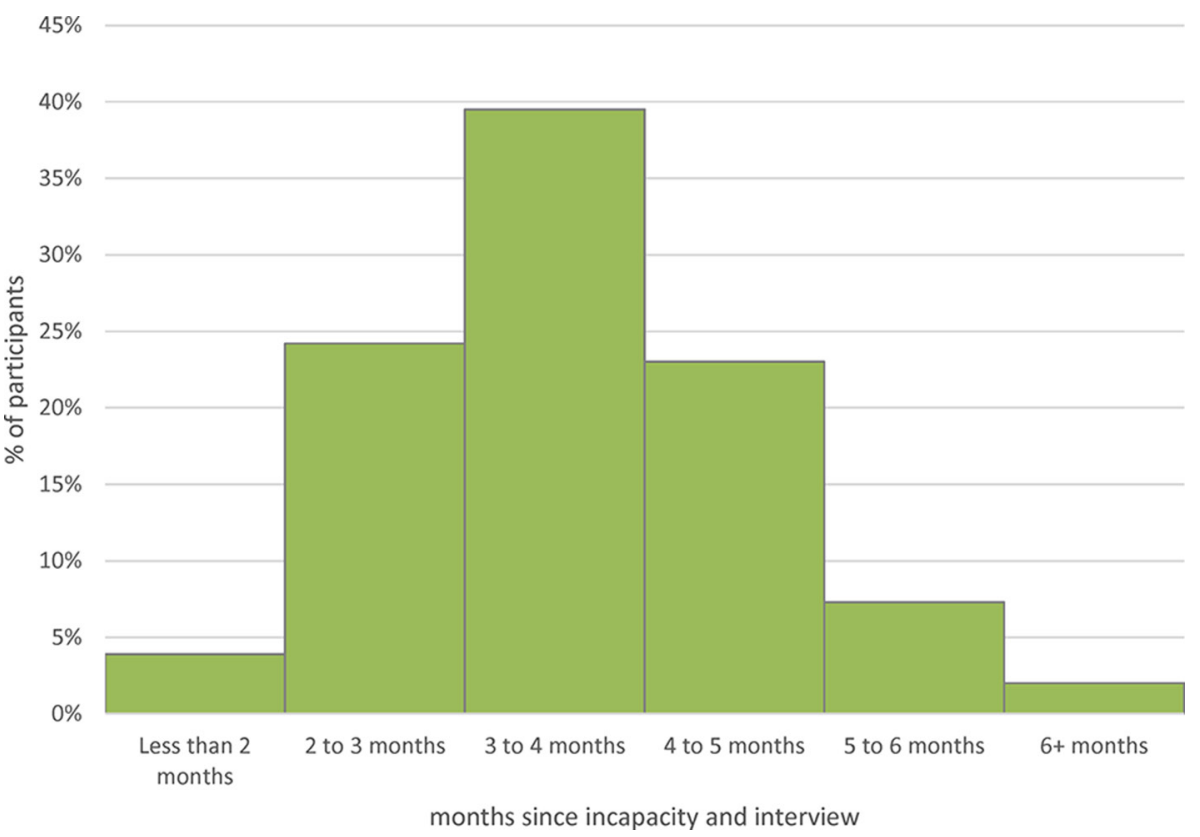

Figure 1 Time between the first date of incapacity and date of the baseline interview.

192 (20\%) claimants aged 55 and over, assuming similar rates of attrition over the study period.

\section{Recruitment}

The cohort includes workers compensation claimants in Victoria (covered by the WorkSafe Scheme), who were interviewed at three time points: as soon as possible after their claim was accepted (baseline), and again at 6 and 12 months after the baseline interview. To recruit this sample, each month WSV identified a random sample of claimants with psychological and MSK injuries using WSV's internal system for classifying the nature of injury/ disease (VCODE). Eligible MSK conditions included all soft-tissue injuries of the back or upper extremity. Injuries to nerves and spinal cord, arthropathies, osteopathies, chondropathies and acquired MSK deformities, fibromyalgia, cervicalgia and arthritic conditions were excluded. For psychological injuries, all injuries where the nature of injury classification (VCODE) indicated a mental disorder, including post-traumatic stress disorder, other reactions to stressors and other mental disorders, not elsewhere classified were considered eligible for inclusion. General exclusions included cases where less than 10 days of absence had occurred, where multiple injuries were sustained by the worker, or where the worker was less than 18 years of age.

The baseline sample was recruited over a 12-month period (June 2014-July 2015), with the first monthly sample from WSV consisting of 405 claimants, and the sample for each of the remaining 11 months consisting of 190 claimants, on average. Each sample member was sent a primary approach letter (PAL) with the option to opt out of the study over the following 3-week period by contacting WSV, by phone, email or surface mail. Contact details of claimants who did not opt out were then provided to an external interviewing agency, to approach each claimant to invite them to participate in the study.

A total of 2495 claimants were included in the sampling frame. Of the 2495 claimants that were sent a PAL, $321(13 \%)$ opted out of the study. Attempts to contact the remaining 2174 claimants were made by the interviewing agency. Of the 2174 claimants where contact was attempted, 50 (2\%) did not have a valid contact number (number disconnected, named person not known, etc), and $82(4 \%)$ were ineligible to participate in the study (injury not in-scope, less than 18 years of age or less than 10 days of total absence from work). Of the remaining sample of 2042 claimants, no contact could be made with 271 claimants; 769 refused to participate in the study and 118 could not participate due to other circumstances (respondent away, ill health, etc). This left a final sample of 869 claimants (36\% of the eligible sample and $49 \%$ of the sample where contact was made).

Figure 1 presents the distribution of the time between the first date of incapacity (defined by the date of the first certificate of incapacity related to the injury) and the date of the baseline interview among the sample who agreed to data linkage. The majority of respondents were interviewed between 2 and 5 months after their first day of incapacity, with the most common time period being between 3 and 4 months. The median time between the first date of incapacity and the interview was 110 days, with the median time between the start of compensation eligibility and the interview date being 93 days. This relatively long time period between the first day of incapacity (and first day of compensation eligibility) and the baseline interview date can be explained as follows. The first date of incapacity marks the start of a work absence. After 10 working days of absence, a claim is submitted to WSV, at which point it becomes eligible for wage replacement from WSV. WSV has 28 days to 
Table 1 Comparison of participants to non-participants from a source population* of workers' compensation claimants in Victoria

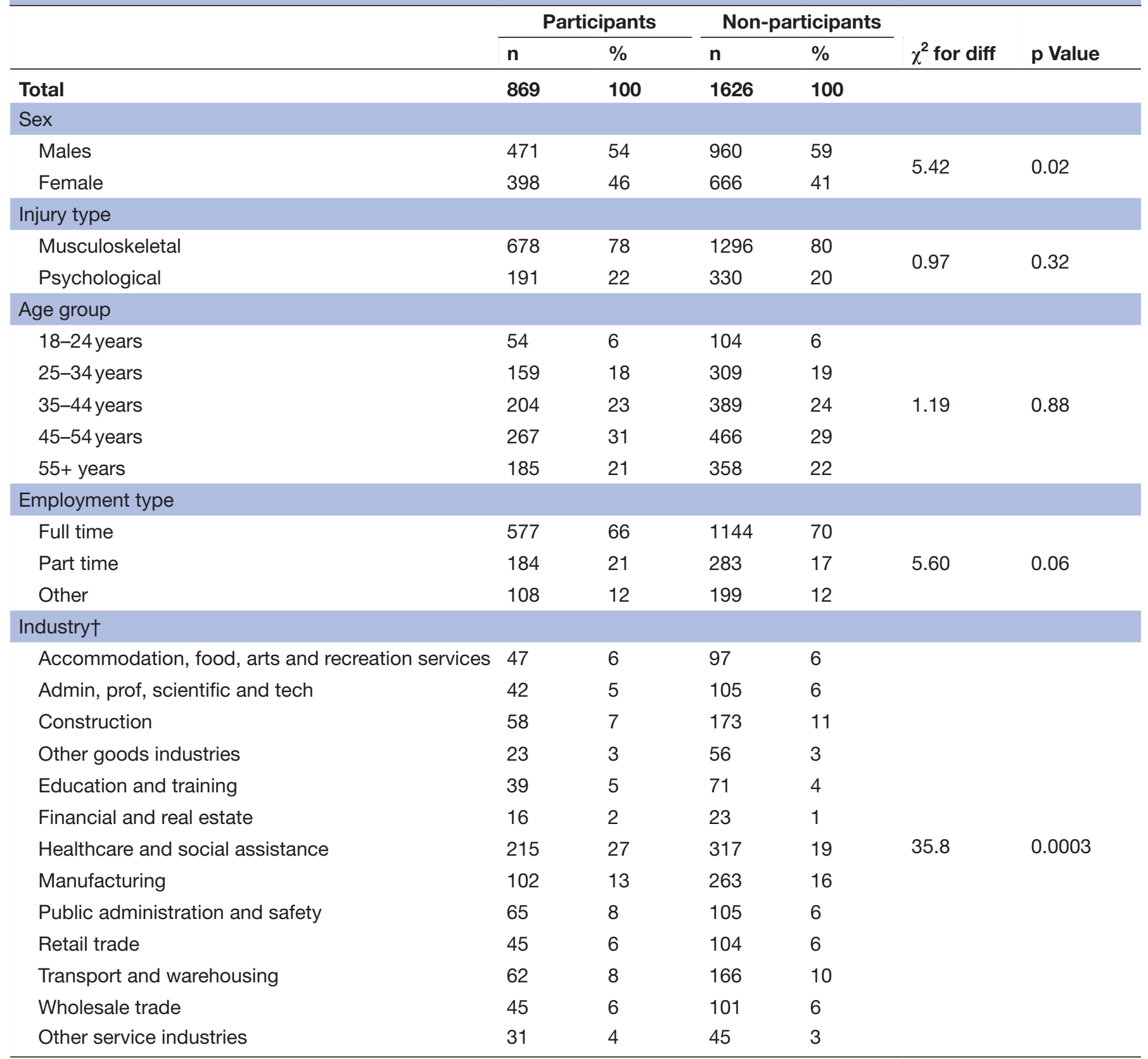

*Source population refers to a random sample of all relevant claims in line with the study criteria during the period of observation. †For participants, industry information is only available for the 790 respondents $(91 \%)$ who agreed to have their survey data linked to their administrative claim record.

adjudicate a claim for workers' compensation. At this point, if the claim is accepted, compensation is backdated to the day of eligibility, and the claim is eligible to be recruited into the cohort. As the selection of claims is only undertaken once a month, the time period between the claim acceptance and when the claim is selected for the cohort could be from a couple of days, to a month. It took approximately 1 week for the PALs to be sent to each claimant. Three weeks after this date attempts to contact the claimant were made from the interviewing company, with attempts continuing for up to 2 months, or until the claimant was contacted.

\section{Participants}

Descriptive data for the 869 claimants who participated in the study, compared with the non-participants $(n=1626)$, from the total source population of 2495 claimants are shown in table 1 . Due to privacy concerns regarding the level of detailed information that could be provided about the source population from WSV, comparisons between participants and non-participants are only possible by sex, age group, injury type, employment type and industry of employment. Focusing on our primary variables of interest (injury type and age), the sample 


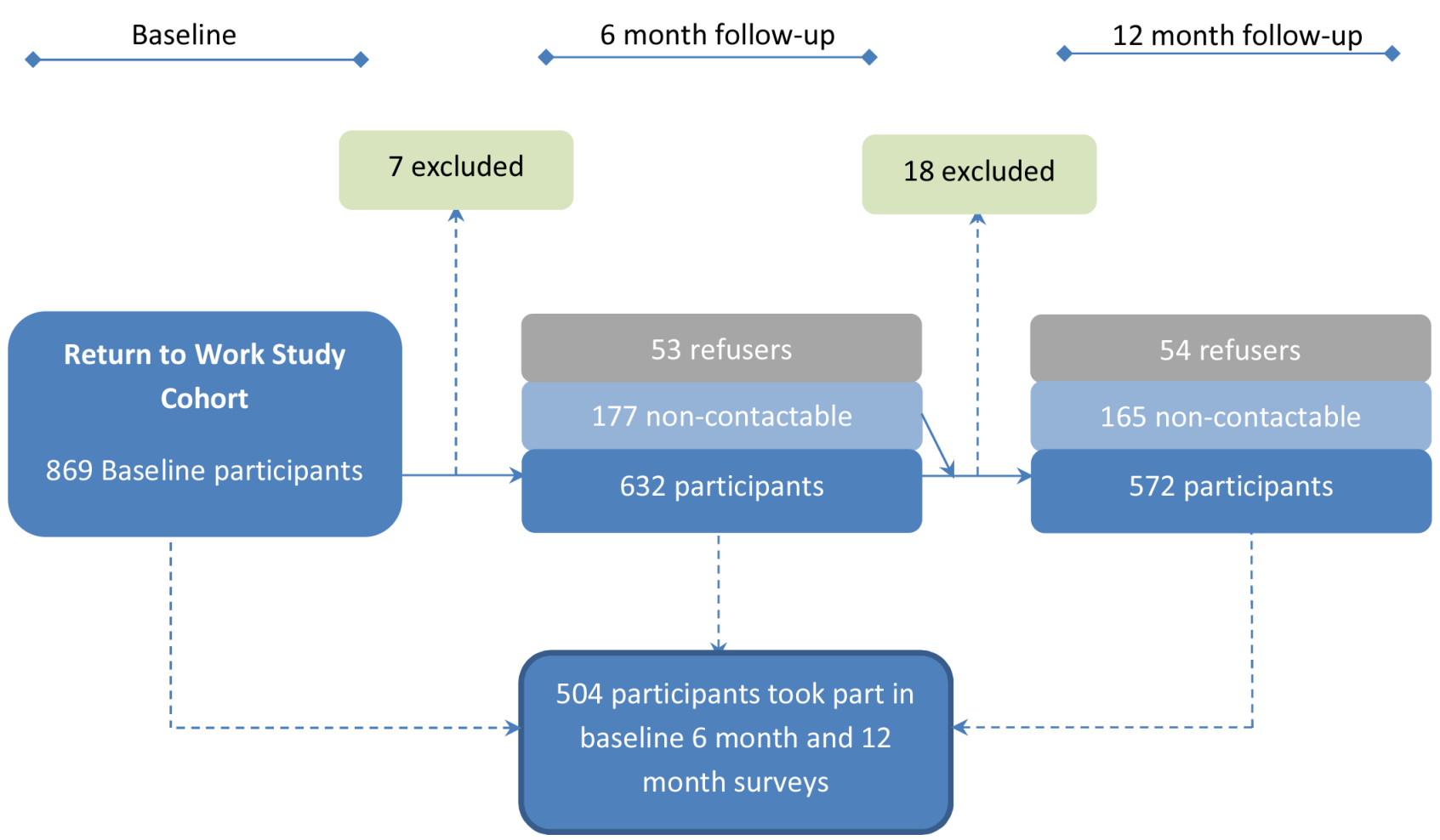

Figure 2 Return to work study, participation and loss to follow-up.

recruited contained 191 (22\%) participants who had a psychological injury and 185 (21\%) participants aged 55 years and older. These proportions were not significantly different to those in the non-participant group.

Statistically significant differences were noted between the sample recruited and non-participants across sex and industry of employment, with borderline differences also observed across employment type. Compared with the non-responders, the sample recruited contained more women and a greater proportion of workers in the healthcare and social assistance industry, and fewer workers in manufacturing and construction industries. Given the nature of the data available on non-responders, it was not possible to determine if industry differences were simply a function of different patterns of response for men and women or reflect differences in response according to specific industry context.

Participation and loss to follow-up in the cohort is presented in figure 2. Of the 869 claimants who participated at baseline, $632(73 \%)$ took part in the 6-month follow-up interview (between January 2015 and January 2016), and $572(66 \%)$ took part in the 12-month follow-up interview (between July 2015 and July 2016). Claimants who were not contactable at the 6-month follow-up interview were also invited to participate at the 12-month follow-up (ie, only participated at baseline and 12-month follow-up interview, with the 6-month follow-up interview missing). Of the 572 participants who completed a 12-month follow-up interview, 504 took part in all three surveys ( $58 \%$ of the baseline sample). The most common reason for non-participation at follow-up was that the claimant was not contactable (19\%). A small proportion of claimants $(3 \%)$ were excluded from follow-up as they were deemed unsuitable to participate further. A further $12 \%$ of claimants refused to participate in the follow-up interviews.

Of the 869 participants recruited at baseline, a total of $790(91 \%)$ agreed to link their survey responses to WSV administrative data, which allows a passive follow-up of respondents using administrative data on payments and services received related to their injury.

Table 2 shows participant's work characteristics at the time of injury (collected at baseline). The majority of participants $(85 \%)$ had been working with the same employer for a year or more at the time of their injury. Participants were predominately permanent employees $(87 \%)$, with $12 \%$ of participant's temporary employees at the time of injury. Approximately, 38\% of participants were shift workers and approximately $75 \%$ worked 35 hours or more per week at the time of injury.

\section{Questionnaire}

Table 3 describes the survey content at each data collection phase. The baseline questionnaire included a combination of questions adapted from previous cohort studies on RTW, as well as questions developed in consultation with stakeholders with experience in RTW. The survey content included work characteristics, demographic information, current working status, RTW arrangements and fairness of the RTW process. In addition, questions about perceptions of recovery and likelihood of RTW, information on current health status (both physical and psychological), preinjury work ability and chronic conditions, disability due to work injury, information on the 
Table 2 Participant work characteristics at time of injury

\begin{tabular}{lll}
\hline & \multicolumn{2}{c}{ Participants } \\
\cline { 2 - 3 } & $\mathbf{n}$ & $\%$ \\
\hline Total & $\mathbf{8 6 9}$ & $\mathbf{1 0 0}$ \\
Job tenure & 67 & 8 \\
$\quad<6$ months & 62 & 7 \\
7 to $<12$ months & 739 & 85 \\
$\geq 12$ months & & \\
Hours per week & 216 & 25 \\
$\quad<35$ hours & 647 & 74 \\
$\quad \geq 35$ hours & & \\
Shift work & 332 & 38 \\
$\quad$ Yes & 527 & 61 \\
No & & \\
\hline Contract & 102 & 12 \\
\hline Temporary & 759 & 87 \\
\hline Permanent & & \\
\hline
\end{tabular}

*Subsamples within groupings may not add up to 869 due to missing data on selected indicators.

preinjury work environment, self-efficacy to RTW and motivation to work were included. Each participant was screened at the beginning of the baseline interview to ensure eligibility. Information on the type of injury, time since injury and number of days off work was collected during the screening process. The duration of the baseline survey was approximately 40 minutes.

As the follow-up surveys excluded various questions where responses would not change (eg, preinjury job), the duration was approximately 30 minutes. Additional questions were also added to the 6-month interview relating to general perceptions on the claim process, involvement of lawyers, disagreement in the claim process and sleep disturbance. The 12-month interview included additional questions regarding income and type of support/assistance received.

Participants were asked for consent to have their survey responses linked to their workers' compensation administrative data. The datasets available for linkage included the WSV claims database (claimant, workplace and claim/ injury information), payment database (payment information), services database (healthcare and non-health care services received that are related to the respondent's injury) and Medical Certificate database. Linkage to WSV administrative data allows examination of wage replacement and healthcare service use prior to, and in between interviews, as well as longer term administrative follow-up of participants.

\section{FINDINGS TO DATE}

Sociodemographic characteristics of the cohort at baseline and follow-up interviews are shown in table 4 . Gender, injury type and country of birth proportions did not significantly change from baseline to follow-up interviews, with an identical proportion of participants in each group at all three time points. Between the baseline interview and the follow-up interviews, an increasing proportion of the sample was aged 55 years and older and a decreasing proportion was aged less than 35 years. These changes in the age distribution of the sample were a function of greater loss-to-follow-up of younger claimants. Participant's current working status (modified or pre-injury duties) increased from the baseline interview to the 6-month follow-up interview; however, no significant change from the 6-month to 12-month follow-up interview was observed.

Logistic regression analysis was undertaken at baseline to examine the probability of non-participation at follow-up interviews (results not shown, but available on request). Gender, age, injury type and working status at baseline were included in the analysis as potential predictors of non-participation. Age was the only statistically significant predictor observed, with claimants aged between 18 and 34 almost half as likely to participate in the 6-month and 12-month follow-up, compared with the subgroup aged between 35 and 54. Claimants aged 55 and over were almost twice as likely to participate at the follow-up interviews, compared with the subgroup aged between 35 and 54 .

Examination of whether particular types of respondents were more or less likely to agree to link their responses to their survey data was undertaken. The logistic regression analysis (results not shown, but available on request), including injury type, sex, age group and work status at the baseline interview found that male respondents were less likely to provide permission to link to their survey responses $(88 \%)$, compared with female respondents $(94 \%)$. No differences in agreement to link were found across injury type, age group or work status at baseline.

\section{STRENGTHS AND LIMITATIONS}

The cohort is one of the first we are aware of that has been designed to compare RTW from work-related MSK and psychological injuries using a longitudinal study design and data linkage. As the study aims to collect data at three time points over a 12-month period, the data will provide insight into potential intervention points during the RTW process to reduce inequalities in RTW and other outcomes between psychological and physical injuries and across age groups. In addition, the longitudinal data collected will allow the examination of how these factors, as well as RTW status and recovery measures, change over time.

The final sample of respondents recruited totalled 869 , which was 91 claimants short of our target, although slightly higher than expected samples of psychological claimants and claimants aged 55 years and older were recruited in the baseline survey. This should still enable adequate power to detect expected differences in RTW 


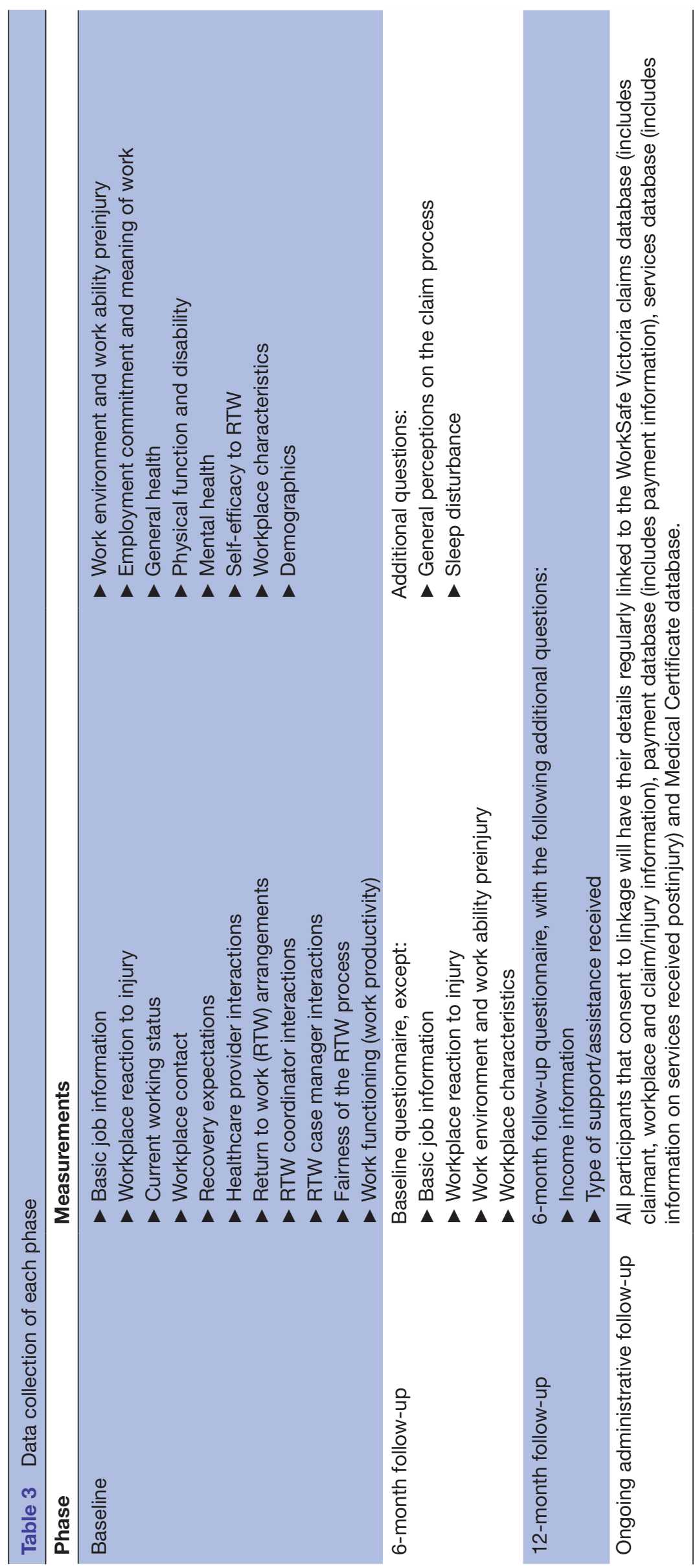


Table 4 Sociodemographic characteristics of return to work (RTW) cohort at baseline and 6 and 12 month follow-up

\begin{tabular}{|c|c|c|c|c|c|c|}
\hline & \multicolumn{2}{|c|}{ Baseline } & \multicolumn{2}{|c|}{6 month follow-up } & \multicolumn{2}{|c|}{12 month follow-up } \\
\hline & $\mathbf{n}$ & $\%$ & $\mathbf{n}$ & $\%$ & $\mathbf{n}$ & $\%$ \\
\hline Total & 869 & 100 & 632 & 100 & 572 & 100 \\
\hline Male & 471 & 54 & 347 & 55 & 312 & 55 \\
\hline Female & 398 & 46 & 285 & 45 & 260 & 45 \\
\hline \multicolumn{7}{|l|}{ Injury type } \\
\hline Musculoskeletal & 678 & 78 & 495 & 78 & 443 & 77 \\
\hline Psychological & 191 & 22 & 137 & 22 & 129 & 23 \\
\hline \multicolumn{7}{|l|}{ Age group } \\
\hline$<35$ years & 213 & 25 & 132 & 21 & 106 & 19 \\
\hline $35-54$ years & 471 & 54 & 346 & 55 & 317 & 55 \\
\hline Australia & 636 & 73 & 458 & 72 & 425 & 74 \\
\hline Other & 232 & 27 & 174 & 28 & 147 & 26 \\
\hline \multicolumn{7}{|l|}{ Working status } \\
\hline Currently working & 512 & 59 & 439 & 69 & 388 & 68 \\
\hline Not currently working & 357 & 41 & 193 & 31 & 184 & 32 \\
\hline
\end{tabular}

*Subsamples do not add up to 869 due to missing data.

outcomes at the 12-month interview as the overall attrition over the study period was lower than predicted.

The majority of respondents were interviewed between 2 and 5 months after their first day of incapacity, with the most common time period being between 3 and 4 months. As claimants were interviewed on average 3-4 months after their claim was accepted, recall of certain details such as preinjury work environment may be challenging. The overall baseline recruitment rate of $36 \%$ is a potential limitation; however, a higher than expected retention rate was achieved at follow-up, with response rates of $73 \%$ at first follow-up and $66 \%$ at second follow-up.

WSV administrative data will allow a passive follow-up of respondents using payments, services and wage replacement data into the future.

\section{LESSONS LEARNT}

While the assembly of this RTW cohort will provide important information on differences in the RTW process for older claimants, compared with younger claimants, as well as for psychological injury claims compared with MSK claims, there are also potential areas related to the recruitment of a workers' compensation sample that could be incorporated into future projects in this area. The first is to incorporate measures that might enable a more rapid recruitment of potential respondents following the initial claim for injury. While some of these features are structural to the workers' compensation system in Victoria (eg, having to accumulate 10 days of absence from work before a claim is submitted), other features such as the time taken to adjudicate injury claims, and the timing when claims are identified for inclusion (eg, weekly vs monthly) are potentially modifiable. The complexity of the adjudication of psychological injury claims often leads to the full 28 days (and sometimes longer) being taken before these claims are accepted. Future studies examining these more complex injury claims might attempt to recruit respondents earlier in the claim process (eg, after claim submission rather than claim acceptance). However, any approach like this would need to balance the acceptance rate of these injury claims, as well as the stressful and often overwhelming nature of the initial claim submission process. In this cohort, we used strategies (eg, contact in between surveys) to minimise lossto-follow-up over the 12-month study period. While our loss-to-follow-up was lower than expected, we did still have differential loss-to-follow-up among younger respondents. In many cases, this loss to follow-up was due to inability to contact the claimant. We do not know the extent to which our inability to contact these claimants was due to their contact details changing or active efforts of the respondent not to be contacted for future surveys. Future work should attempt to collect multiple mediums through which claimants could be contacted for future surveys, to help reduce loss to follow-up due to non-contact.

Acknowledgements We would like to acknowledge the Social Research Centre (SRC) for undertaking the interviews. We acknowledge the assistance of WorkSafe Victoria, SafeWork Australia, Office of The Age Discrimination Commissioner, Beyond Blue and the Australian Industry Group.

Collaborators The data are held at Monash University, Department of Epidemiology and Preventive Medicine, School of Public Health and Preventive 
Medicine. Procedures to access data from this study are available through contacting the lead author. Proposals for collaborative analyses will be considered by the study's investigator team.

Contributors CD was involved in the coordination of the study and wrote the initial manuscript and approved the final manuscript as submitted. ADL, RL, SHJ, MS and PS were involved in the development of the study protocol and the acquisition of research funding for this project. They each revised the manuscript critically for important intellectual content and approved the final manuscript as submitted. PS is the principal investigator for the study. He led the conceptualisation, development and design of the study.

Funding This study is funded through the Australian Research Council (ARC) linkage grant Project number LP130100091.

Ethics approval The study is approved by the Monash University Human Research Ethics Committee.

Provenance and peer review Not commissioned; externally peer reviewed.

Data sharing statement Procedures to access data from this study are available through contacting the lead author (CD). Proposals for collaborative analyses will be considered by the study's investigator team. The study questionnaire can be provided by contacting the lead author (CD).

Open Access This is an Open Access article distributed in accordance with the Creative Commons Attribution Non Commercial (CC BY-NC 4.0) license, which permits others to distribute, remix, adapt, build upon this work non-commercially, and license their derivative works on different terms, provided the original work is properly cited and the use is non-commercial. See: http://creativecommons.org/ licenses/by-nc/4.0/

(C) Article author(s) (or their employer(s) unless otherwise stated in the text of the article) 2017. All rights reserved. No commercial use is permitted unless otherwise expressly granted.

\section{REFERENCES}

1. Safe Work Australia. Key workers' compensation information, Australia 2014. Canberra, ACT: Safe Work Australia, 2015.

2. Safe Work Australia. Comparison of workers' compensation arrangements in Australia and New Zealand. Canberra, ACT: Safe Work Australia, 2011.

3. Ostry A. From chainsaws to keyboards: injury and industrial disease in British Columbia. In: Sullivan T, ed. Injury and the new world of work. Vancouver: UBC Press, 2000:27-45.

4. Safe Work Australia. Australian work-related injury experience by sex and age, 2009-2010. Canberra, ACT: Safe Work Australia, 2012.

5. Safe Work Australia. Compendium of workers' compensation statistics: Australia 2009-2010. Canberra, ACT: Safe Work Australia, 2012.

6. Safe Work Australia. The incidence of accepted workers' compensation claims for mental stress in Australia. Canberra, ACT: Safe Work Australia, 2013.

7. Berecki-Gisolf J, Clay FJ, Collie A, et al. The impact of aging on work disability and return to work: insights from workers' compensation claim records. J Occup Environ Med 2012;54:318-27.

8. Comcare. Psychological injury and performance. Canberra ACT: Comcare, Federal Government. https://www.comcare.gov.au/_ data/assets/pdf_file/0017/134315/Psychological_Injury_and_ Performance_PDF,_661_KB.pdf
9. IImarinen JE. Aging workers. Occup Environ Med 2001;58:546-52.

10. Smith P, Bielecky A, Mustard C, et al. The relationship between age and work injury in British Columbia: examining differences across time and nature of injury. J Occup Health 2013;55:98-107.

11. Silverstein M. Meeting the challenges of an aging workforce. Am J Ind Med 2008;51:269-80.

12. Mental Health Commission of Canada. Making the case for investing in mental health in Canada. Ottawa, Ontario, Mental Health Commission of Canada 2013

13. Furlan AD, Gnam WH, Carnide N, et al. Systematic review of intervention practices for depression in the workplace. J Occup Rehabil 2012;22:312-21.

14. Pomaki G, Franche RL, Murray E, et al. Workplace-based work disability prevention interventions for workers with common mental health conditions: a review of the literature. J Occup Rehabil 2012;22:182-95.

15. Knauf MT, Schultz IZ. Current conceptual models of return to work In: Schultz IZ, Gatchel RJ, eds. Handbook of return to work: from research to practice, New York, NY: Springer Science and Business Media. 2016:27-51.

16. Loisel P, Durand M-J, Berthelette D, et al. Disability prevention. Dis Manage Health Outcomes 2001;9:351-60.

17. Pransky GS, Loisel P, Anema JR. Work disability prevention research: current and future prospects. J Occup Rehabil 2011;21:287-92.

18. Dasinger LK, Krause N, Thompson PJ, et al. Doctor proactive communication, return-to-work recommendation, and duration of disability after a workers' compensation low back injury. J Occup Environ Med 2001;43:515-25.

19. Franche RL, Cullen K, Clarke J, et al. Workplace-based return-towork interventions: a systematic review of the quantitative literature. J Occup Rehabil 2005;15:607-31.

20. Iles RA, Davidson M, Taylor NF. Psychosocial predictors of failure to return to work in non-chronic non-specific low back pain: a systematic review. Occup Environ Med 2008;65:507-17.

21. Kosny A, Franche RL, Pole J, et al. Early healthcare provider communication with patients and their workplace following a losttime claim for an occupational musculoskeletal injury. J Occup Rehabil 2006;16:27-39.

22. Kosny A, MacEachen E, Ferrier S, et al. The role of health care providers in long term and complicated workers' compensation claims. J Occup Rehabil 2011;21:582-90.

23. Laisné $F$, Lecomte $\mathrm{C}$, Corbière $\mathrm{M}$. Biopsychosocial predictors of prognosis in musculoskeletal disorders: a systematic review of the literature. Disabil Rehabil 2012;34:355-82.

24. Hoefsmit N, Houkes I, Nijhuis FJ. Intervention characteristics that facilitate return to work after sickness absence: a systematic literature review. J Occup Rehabil 2012;22:462-77.

25. van Vilsteren $\mathrm{M}$, van Oostrom $\mathrm{SH}$, de Vet $\mathrm{HC}$, et al. Workplace interventions to prevent work disability in workers on sick leave. Cochrane Database Syst Rev 2015;10:CD006955.

26. Chambers A, Smith PM, Sim MR, et al. Comparison of two measures of work functioning in a population of claimants with physical and psychological injuries. Qual Quant 2017;51:425-34.

27. Smith PM, Berecki-Gisolf J. Age, occupational demands and the risk of serious work injury. Occup Med 2014;64:571-6.

28. Pearce D, Dubey M. Australian workers' compensation law and its application: psychological injury claims. Canberra, ACT: Safe Work Australia, 2006

29. Safe Work Australia. Comparison of workers' compensation arrangements in Australia and New Zealand. Canberra, ACT: Safe Work Australia, 2015. 